\title{
Laboreal
}

Volume $14 \mathrm{~N}^{\circ} 2$ | 2018

Digitalização e evolução do trabalho real

\section{Digitalização do trabalho no INSS: tensões e estratégias de regulação na implementação do novo modelo de atendimento}

Digitalización del trabajo en el INSS: tensiones y estrategias de regulación en la implementación del nuevo modelo de atención

Digitalisation du travail au sein de l'INSS: tensions et stratégies de régulation dans la mise en cuvre du nouveau modèle de service

Digitalization of work at INSS: tensions and strategies of regulation in the implementation of the new service model

\section{Sacha Pinheiro, Marta Santos e Liliana Cunha}

\section{OpenEdition}

\section{Journals}

\section{Edição electrónica}

URL: http://journals.openedition.org/laboreal/650

DOI: $10.4000 /$ laboreal. 650

ISSN: 1646-5237

\section{Editora}

Universidade do Porto

\section{Refêrencia eletrónica}

Sacha Pinheiro, Marta Santos e Liliana Cunha, « Digitalização do trabalho no INSS: tensões e estratégias de regulação na implementação do novo modelo de atendimento », Laboreal [Online], Volume $14 \mathrm{~N}^{\circ} 2$ | 2018, posto online no dia 01 dezembro 2018, consultado o 10 dezembro 2020. URL : http://journals.openedition.org/laboreal/650 ; DOI : https://doi.org/10.4000/laboreal.650

Este documento foi criado de forma automática no dia 10 dezembro 2020

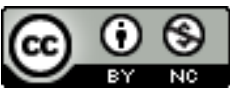

Laboreal está licenciado com uma Licença Creative Commons - Atribuição-NãoComercial 4.0 Internacional. 


\section{Digitalização do trabalho no INSS: tensões e estratégias de regulação na implementação do novo modelo de atendimento}

Digitalización del trabajo en el INSS: tensiones y estrategias de regulación en la implementación del nuevo modelo de atención

Digitalisation du travail au sein de l'INSS: tensions et stratégies de régulation dans la mise en cuvre du nouveau modèle de service

Digitalization of work at INSS: tensions and strategies of regulation in the implementation of the new service model

Sacha Pinheiro, Marta Santos e Liliana Cunha

\section{NOTA DO EDITOR}

http://dx.doi.org/10.15667/laborealxiv218sp

Manuscrito recebido em: julho/2018

Aceite após peritagem: outubro/2018

\section{Introdução}

1 Nas últimas décadas, o desenvolvimento das tecnologias da informação e comunicação tem contribuído para o desenho de um 'novo mundo do trabalho', dando novos contornos à atividade profissional nos contextos industriais ou de serviços, nos setores público ou privado. Esta questão tem sido objeto de crescente interesse científico, a partir de recortes variados que incluem: a natureza da relação homem-tecnologiaorganização (Brangier \& Hammes, 2007); as transformações no trabalho e as 
repercussões para a saúde (Bobillier Chaumon, 2003; Cuvelier \& Caroly, 2011; Picard, 2007; Caroly, 2007); a construção de relações mediatizadas entre usuário e trabalhador no âmbito da prestação de serviços (Dubois \& Bobillier Chaumon, 2007); as implicações para os coletivos profissionais (Cuvelier \& Caroly, 2011); ou os riscos de exclusão de trabalhadores, com atenção especial para aqueles de mais idade ou antiguidade na organização (Friedberg, 2003; Pavageau, Nascimento \& Falzon, 2007; Cros, Bobillier Chaumon \& Cuvillier, 2016).

2 De forma geral, estas novas tecnologias têm sido abordadas em uma dupla perspectiva: como fonte de recursos para o desenvolvimento da atividade e das competências; ou como fonte de constrangimentos (relacionados, por exemplo, à intensificação da carga de trabalho ou ao estreitamento das fronteiras entre vida privada e vida profissional (Caroly, 2007; Bobillier Chaumon, 2003; Cros, et al., 2016). Isto sugere que a articulação entre tecnologia e trabalho está longe de ser linear, desvelando uma complexa e ambivalente relação entre tecnologia, atividade e sujeito (Bobillier Chaumon \& Clot, 2016).

3 Gerir informações digitais, tratá-las e comunicá-las constituem-se como competências cada vez mais solicitadas (Kessous \& Metzger, 2005, apud Pavageau, et al., 2007). A mediação por artefatos tecnológicos exige formas diferentes de fazer, de interagir; muda-se a proximidade com o objeto do trabalho, lida-se com mais abstrações, exigemse mais operações intelectuais, influenciando a carga mental associada à atividade (Bobillier Chaumon, 2003).

4 Neste contexto, surgem novos desafios para o campo da saúde no trabalho e colocam-se importantes reflexões quanto à relação do trabalhador com sua atividade: em que medida a dinâmica das situações concretas tem sido considerada na concepção e implementação destas ferramentas, de forma a funcionarem como recursos ao desenvolvimento da atividade? Ou, pelo contrário, em que medida a tecnologia tem funcionado como instrumento de prescrição e controle, diminuindo as margens para a expressão do trabalhador e do seu poder de agir?

5 A compreensão das implicações da integração das tecnologias às práticas profissionais não pode prescindir da análise das situações concretas de trabalho. Análises que sejam capazes de evidenciar as formas de apropriação das novas ferramentas, e de que forma estas condições de apropriação têm favorecido sua transformação em instrumentos que façam sentido para o trabalhador em seu contexto de uso.

6 As discussões aqui propostas buscam contribuir para o debate acerca dos impactos da integração das novas tecnologias na atividade profissional, a partir da análise sobre as transformações em curso no Instituto Nacional do Seguro Social - INSS ${ }^{1}$, organização do serviço público federal brasileiro responsável pelo gerenciamento da política de Previdência Social no Brasil. Diversas iniciativas pautadas na melhoria da gestão do atendimento vêm sendo empreendidas no INSS nos últimos anos, culminando na recente concepção do 'Projeto INSS Digital: uma nova forma de atender [2]', que vem sendo paulatinamente expandido para todas as unidades de atendimento do país.

7 Tem-se como objetivo analisar o projeto de digitalização no INSS a partir das seguintes questões de investigação: (1) que tensões/conflitos se colocam para os servidores na integração das tecnologias à sua atividade? (2) que margens de manobra são possíveis e que estratégias de regulação são elaboradas na interação com as ferramentas? 
8 Sabe-se já que as inovações implementadas têm transformado substancialmente a atividade nas unidades de atendimento do INSS, as chamadas Agências da Previdência Social (APS). Com a digitalização do trabalho, progressivamente, as ferramentas tecnológicas se interpõem como mediadoras da relação dos trabalhadores com os usuários e destes com a instituição, a partir da ampliação dos serviços online e da externalização de parte das atividades do INSS.

Estas transformações têm sido objeto de debate entre servidores e suas entidades sindicais representativas, no sentido de compreender as implicações futuras tanto para os trabalhadores como para os usuários, e delinear estratégias para a proteção da saúde no trabalho neste cenário de digitalização.

10 A partir de estudo de terreno que incluiu servidores que atuam com a análise de benefícios previdenciários em diferentes unidades, e em situações em que o processo de digitalização se encontra em fases distintas, pretende-se articular os discursos destes atores na compreensão da mudança da organização do trabalho em curso.

\section{Referencial teórico}

11 Este estudo ancora-se nos fundamentos das tradições científicas da Psicologia do Trabalho e da Ergonomia da Atividade de origem francófona (Guérin, Laville, Daniellou, Duraffoug, \& Kerguelen, 2001; Wisner, 1995; Teiger, 1993; Lacomblez, 1997). Estas referências situam-nos num campo de compreensão que toma o trabalhador não apenas como mero executante do trabalho prescrito, mas como criador de sua própria atividade. Privilegia-se, assim, uma abordagem atenta ao que se passa nas situações reais, ciente de que há muito mais em jogo no trabalho do que a execução de normas e procedimentos determinados externamente.

12 Embora presente a dimensão do protocolo, das normas, há também a dimensão do invisível, daquilo que emerge nas situações reais de trabalho e que envolve a ação do trabalhador, a partir de arbitragens que realiza na tentativa de conciliar os objetivos organizacionais, as demandas do real do trabalho, seus valores e sua saúde (Borba \& Muniz, 2017).

13 A atividade de trabalho, mobilização da pessoa humana (considerada na integralidade de seus aspectos físicos, cognitivos, subjetivos, sociais), é construída permanentemente em um quadro de objetivos e restrições, através da mobilização de diferentes recursos. Ela integra dimensões relacionadas ao meio ambiente de trabalho e às características do trabalhador, que ultrapassam a possibilidade de observação no aqui e agora (Guérin, et al, 2001).

14 Trabalhar é, portanto, produzir uma resposta original que deve articular um vasto conjunto de determinantes, os quais orbitam em torno de duas principais esferas de interesses: os relativos aos próprios trabalhadores (a saúde, as competências, as dimensões subjetivas); e os relativos à produção (Béguin, 2006). Diante destas exigências muitas vezes difíceis de conciliar, os trabalhadores desenvolvem estratégias de regulação com o intuito de gerir o equilíbrio entre o cumprimento das normas de produção e a proteção de sua saúde.

15 Em articulação com esses referenciais teóricos, entende-se a apropriação das ferramentas tecnológicas não como uma interiorização, pelos trabalhadores, dos funcionamentos exteriores definidos pelos conceptores; mas sobretudo como uma 
recriação, voltada para a construção de novos sentidos para estas ferramentas (Clot, 2010). Ou, como propunha Rabardel (1995), o que está aqui em causa é a diferença entre artefatos e instrumentos. Para o autor, um artefato só se torna um verdadeiro instrumento quando se inscreve em uma utilização, quando é um meio para o utilizador poder realizar um determinado objetivo. Considera-se o instrumento, portanto, como uma entidade mista que reúne em si um artefato (material ou simbólico), e os esquemas de utilização que são construídos pelo sujeito, ou resultantes da apropriação de esquemas sociais já existentes (Santos \& Lacomblez, 2016).

Assim, longe de qualquer determinismo tecnológico, o indivíduo não fica passivo frente aos novos artefatos/ferramentas, pois ele tem a capacidade de agir e reagir para contornar os seus usos, no sentido de os apropriar enquanto instrumentos (Rabardel, 1995) para o desenvolvimento de sua atividade e a preservação da sua saúde (Bobillier Chaumon \& Clot, 2016).

Com efeito, a partir de uma concepção construtiva e criativa, inscrita numa perspectiva que tem sido chamada de clinique de l'usage, inspirada nos paradigmas da clínica da atividade (Clot, 2010), os dispositivos tecnológicos são percebidos para além de seu papel como ferramentas ao serviço da tarefa; como um meio para a renovação e o desenvolvimento da atividade. É sobretudo pelo processo de apropriação das ferramentas tecnológicas, pela inovação que é possibilitada ao indivíduo na sua utilização, que ele poderá reconstruir o artefato para torná-lo um instrumento que faça sentido no seu contexto de uso e, acima de tudo, que dê sentido à atividade que realiza (Rabardel, 1995; Bobillier Chaumon \& Clot, 2016).

18 A tecnologia tem, portanto, uma dupla vocação no trabalho: ela representa um artefato, um meio para realizar a atividade; mas também um instrumento, em gênese e em coconstrução permanente com o operador e o seu sistema de atividade, no qual deve poder realizar-se através do seu poder de agir (Bobillier Chaumon \& Clot, 2016).

Nessa perspectiva, salienta-se a importância de margem de manobra, de um espaço de regulação do sujeito em atividade de trabalho. Este espaço de regulação varia segundo determinantes externos (concepção dos meios de trabalho; natureza das prescrições; regras de ofício; suporte do coletivo; recursos disponibilizados...); e determinantes internos, referentes às características singulares do trabalhador (idade, sexo, competências, percurso na organização...). Fala-se em margem de manobra situacional quando, em uma situação concreta, o trabalhador é capaz de elaborar compromissos operatórios - eficazes com relação ao desempenho, ao mesmo tempo em que são compatíveis com a preservação de si e seu desenvolvimento pelo trabalho (Coutarel, Caroly, Vézina \& Daniellou, 2015).

Estas margens de manobra contribuem, por sua vez, para a ampliação do poder de agir do trabalhador, que se expressa através da criação de novos objetivos, novos destinatários e/ou novos instrumentos da atividade (Clot, 2010).

21 Tendo em vista que a integração das tecnologias ao trabalho pode ser sentida como maior ou menor fonte de constrangimento, uma dinâmica de transição tecnológica precisa acompanhar os atores na apropriação das ferramentas e na modificação de suas práticas com relação à nova atividade de trabalho (Caroly, 2007).

Do contrário, corre-se o risco de exclusão de trabalhadores que vivenciam a integração das novas tecnologias com mais dificuldade. Segundo Pavageau, et al. (2007), a dificuldade de adaptação pode se colocar particularmente para aqueles com mais tempo 
de serviço, os quais construíram suas competências em universos organizacionais mais estáveis. Para estes autores, importa questionar as condições que são oferecidas para o acesso à formação, para o recurso ao coletivo de trabalho, e para a apropriação dos novos modos de fazer a atividade.

Cros, et al. (2016), acerca das condições de desenvolvimento da atividade de trabalhadores de mais idade aquando da integração de novas tecnologias, enfatizam a importância da inserção destes trabalhadores em um coletivo de trabalho. Este coletivo se constitui como recurso essencial na medida em que lhes dá a oportunidade de discutir a atividade e as novas formas de fazer na interação com as ferramentas. Além disso, os autores sublinham a importância da margem de manobra, deste espaço de regulação que possibilite que o trabalhador reconstrua os artefatos técnicos, ampliando seu campo de ação e permitindo o desenvolvimento e a renovação da atividade.

Mais do que as tecnologias elas mesmas, são sobretudo as condições de seu desenvolvimento, de sua implementação e de sua utilização que serão responsáveis pelos efeitos mais ou menos benéficos para a organização e para os trabalhadores (Bobillier Chaumon, 2003). Considerando a complexidade da relação entre sujeito, trabalho e tecnologias, não há uma relação unívoca entre mudanças tecnológicas e efeitos na saúde, sendo impossível predizer como a introdução de uma nova tecnologia específica terá impacto direto na emergência de uma patologia. Isto depende do contexto em que esta tecnologia é implementada, e da variabilidade dos operadores que dela farão uso (Caroly, 2007).

\section{Opções metodológicas}

\subsection{Procedimentos de recolha dos dados}

As reflexões aqui construídas resultam de estudo de terreno realizado entre os meses de setembro e outubro de 2017, e maio a julho de 2018, em unidades do INSS de dois estados da região Nordeste do Brasil [3].

26 A primeira etapa de recolha de dados centrou-se na compreensão das condições envolvidas na implementação do projeto de digitalização do atendimento, a partir de análises documentais e entrevistas semidirigidas a trabalhadores com cargos de gestão envolvidos na concretização da proposta. A segunda etapa correspondeu à análise das situações concretas de trabalho, com o objetivo de compreender as transformações na atividade dos servidores que têm vivenciado a integração das tecnologias nas suas práticas profissionais. Tendo em vista o recorte que se pretendeu dar a este artigo, focado no trabalho real, serão privilegiados os dados recolhidos junto aos servidores sem cargos de gestão.

Optou-se por destacar, neste estudo, as experiências de seis trabalhadores: duas realizam a atividade de análise de processos em meio digital na própria Agência da Previdência Social; e os demais o fazem em polos de análise digital [ ${ }^{4}$. No período da recolha dos dados, momento em que o projeto estava em fase inicial de implementação, ainda não havia trabalhadores em regime de teletrabalho, motivo pelo qual esta situação não será aqui explorada.

Como critérios para a inclusão destes seis participantes, tem-se: (1) atuarem com a análise de benefícios previdenciários [5]; (2) estarem vivenciando a mudança para o 
novo modelo de atendimento em contextos distintos de exercício da atividade. A tabela abaixo identifica estes trabalhadores [6].

Tabela 1: Caracterização dos trabalhadores participantes+

\begin{tabular}{|l|l|l|l|l|}
\hline Participante & Sexo & Idade & Antiguidade no INSS & Local de trabalho \\
\hline Luana & F & 59 anos & 35 anos & Agência da Previdência Social \\
\hline Joyce & F & 52 anos & 33 anos & \\
\hline André & M & 52 anos & 6 anos & Polo de análise digital A \\
\hline Michelle & M & 43 anos & 14 anos & \multirow{2}{*}{ Polo de análise digital B } \\
\hline João & M & 27 anos & 6 anos & \\
\hline Felipe & M & 31 anos & 6 anos & \\
\hline
\end{tabular}

29 A análise da atividade envolveu entrevistas e observações. As entrevistas foram organizadas em dois momentos: o primeiro intencionou resgatar as vivências e percepções quanto à mudança para o novo modelo de atendimento, a partir do convite aos participantes para que falassem livremente sobre esta transição; o segundo momento partiu dos princípios da técnica de 'instrução ao sósia' (Oddonne, Re \& Briante, 1981; Clot, 2010). Para tanto, solicitava-se ao trabalhador que pusesse em palavras a sua atividade, a partir da questão de partida: 'Suponha que eu seja seu sósia e que, amanhã, eu me encontre em uma situação de ter de substituí-lo em seu trabalho. Como você me explicaria sua atividade e como devo proceder?'. Recorrer a este método foi fundamental para evidenciar as estratégias singulares elaboradas pelos trabalhadores no desenvolvimento da atividade. Convidados a descrevê-la com os mínimos detalhes, os participantes recuperaram gestos, esquemas de utilização, pensamentos e valores envolvidos nas suas escolhas quanto à forma de realizar o trabalho.

30 As observações foram realizadas em situações concretas de trabalho, todas acompanhadas de verbalizações simultâneas (em que o trabalhador explicita ao pesquisador detalhes sobre suas ações e sua justificação durante o desenrolar da atividade). Foi possível a realização de dois momentos de observação com cada trabalhador, com durações que variaram entre duas a quatro horas [7].

\subsection{Procedimentos de análise dos dados}

31 O conteúdo da primeira etapa das entrevistas foi transcrito e trabalhado a partir de análise de discurso, seguindo os pressupostos de Orlandi (2008), que defende a ideia do discurso como uma produção de sentidos inscrita em um determinado contexto social, histórico e em certas condições de produção.

O material foi trabalhado a partir da identificação, nos discursos, de trechos ou frases que pudessem ser agrupados em categorias a partir da similaridade entre eles, 
evidenciando as principais tensões vivenciadas pelos trabalhadores com relação à implementação do novo modelo de atendimento.

O conteúdo da segunda parte das entrevistas (na qual se utilizou a técnica de instrução ao sósia), bem como das verbalizações simultâneas e registros das observações, foram analisados na perspectiva de identificar as principais estratégias de regulação e modos operatórios elaborados pelos trabalhadores no desenvolvimento de sua atividade e na interação com as ferramentas tecnológicas.

\section{Resultados}

\subsection{INSS Digital, Uma Nova Forma de Atender. Perspectiva dos Conceptores do Projeto}

34 A análise documental e as entrevistas com os trabalhadores com cargos de gestão permitiram situar o projeto de digitalização sob a perspectiva da organização, identificando as justificativas envolvidas para a mudança do modelo de atendimento, bem como as expectativas acerca das transformações operadas nos fluxos de trabalho.

35 A pertinência do projeto se justifica pela necessidade de responder às diversas restrições à prestação de serviços de qualidade aos cidadãos, tendo em vista: (1) o crescimento da população e o significativo aumento da demanda por serviços do INSS; (2) a diminuição progressiva da força de trabalho na instituição, sem perspectiva de reposição; e (3) a necessidade de economicidade na gestão dos serviços públicos. Seguindo a trilha das recentes tendências de prestação de serviços por meio eletrônico, o projeto propõe a aplicação da tecnologia da informação para viabilizar a externalização de parte das atividades do INSS, fundamentando-se numa perspectiva colaborativa intersetorial de políticas públicas (Instituto Nacional do Seguro Social, 2017).

36 A partir do estabelecimento de acordos de cooperação com organizações públicas ou privadas e da prestação de serviços online, pretende-se ampliar os canais de atendimento da Previdência Social. Esta iniciativa prevê: (1) a redução do fluxo de beneficiários nas unidades de atendimento do INSS (APS); (2) a possibilidade de abertura de mais vagas para novos requerimentos, reduzindo a zero o tempo de espera de atendimento; e (3) a otimização da força de trabalho atual da organização.

37 A perspectiva é que a integração de novas tecnologias favoreça a distribuição mais equilibrada da demanda de requerimentos de benefícios previdenciários entre os servidores analisadores de todo o país, face à possibilidade de realização de análises de processos em meio digital. Além disso, a reorganização dos fluxos de trabalho permite que os servidores analisadores possam concentrar-se exclusivamente na atividade de concessão de benefícios, esperando-se maior celeridade e qualidade nas análises.

38 A redefinição dos fluxos dividiu a atividade de análise de benefícios, anteriormente realizada integralmente pelo servidor analisador numa agência de atendimento (APS), em três etapas: (1) digitalização de documentos; (2) autenticação; (3) análise. As duas primeiras passam a ser realizadas por estagiários/servidores do INSS na APS, ou nas entidades parceiras $\left.{ }^{8}\right]$. O servidor analisador passa a se responsabilizar unicamente pela etapa de análise digital do requerimento. 
O projeto prevê que os analisadores possam realizar suas atividades (1) na própria agência (APS), em espaços reservados para que o servidor não tenha contato com os usuários; (2) em polos de análise digital; (3) em regime de teletrabalho. No primeiro caso, o servidor continua a responder por carga horária diária, com obrigatoriedade de registro eletrônico de frequência. Nos polos digitais e em teletrabalho, os servidores passam a atender metas de produtividade individuais, sem obrigatoriedade de cumprimento de carga horária específica.

A pontuação mensal a ser cumprida foi definida com base no tempo de atendimento estimado para cada serviço no modelo presencial. 0 atendimento presencial de um requerimento de aposentadoria por idade, por exemplo, deveria ser realizado em, no máximo, 60 minutos. Como os servidores têm carga horária de seis horas de trabalho, podiam atender até seis beneficiários requerentes de aposentadoria por dia. Para a análise digital, considera-se que o processo de aposentadoria por idade vale 60 pontos, contabilizando, portanto, uma média mínima de 360 pontos/dia. Assim, definiu-se como meta individual, o cumprimento de 7920 pontos mensais que, distribuídos pelos dias úteis, correspondem a uma média de 360 pontos/dia.

\subsection{O INSS digital e a atividade concreta: o que está para além da concepção do projeto?}

41 Organizamos os resultados nesta segunda seção em momentos distintos, caracterizando as três situações encontradas no estudo de terreno: (1) análise digital realizada na APS; (2) análise em polo digital com exigência de pontuação mínima mensal (polo digital A); (3) análise em polo digital com exigência de pontuação mínima mensal e quantidade de processos analisados por dia (polo digital B).

o primeiro quadro explora as cinco categorias evidenciadas na análise do discurso, articulando a descrição da situação concreta de trabalho com extratos das narrativas dos trabalhadores. $O$ segundo evidencia a dimensão singular da atividade, explorando as estratégias elaboradas pelos trabalhadores na reconfiguração de sua atividade a partir da implementação do projeto 'INSS Digital'.

\subsubsection{Análise digital na agência: 'a meta é de toda a equipe, em conjunto'}

Esta primeira situação é retratada sob a perspectiva de duas servidoras que optaram por não aderir ao trabalho por produtividade nos polos digitais, e têm realizado as análises de requerimentos em meio digital na própria APS. Trata-se de uma agência de grande porte situada na capital de um estado da região Nordeste. A unidade está em fase de transição para o modelo de atendimento digital, sendo que a maior parte da sua demanda ainda é recepcionada de forma presencial.

Quadro I: Vivência de mudança entre os servidores da APS

\begin{tabular}{|l|l|l|l|l|}
\hline $\begin{array}{l}\text { Horário de } \\
\text { trabalho }\end{array}$ & $\begin{array}{l}\text { Metas e controle } \\
\text { de produção }\end{array}$ & $\begin{array}{l}\text { Relação com o } \\
\text { usuário }\end{array}$ & $\begin{array}{l}\text { Formação para e } \\
\text { no trabalho }\end{array}$ & $\begin{array}{l}\text { Digitalização e uso } \\
\text { das ferramentas } \\
\text { tecnológicas }\end{array}$ \\
\hline
\end{tabular}




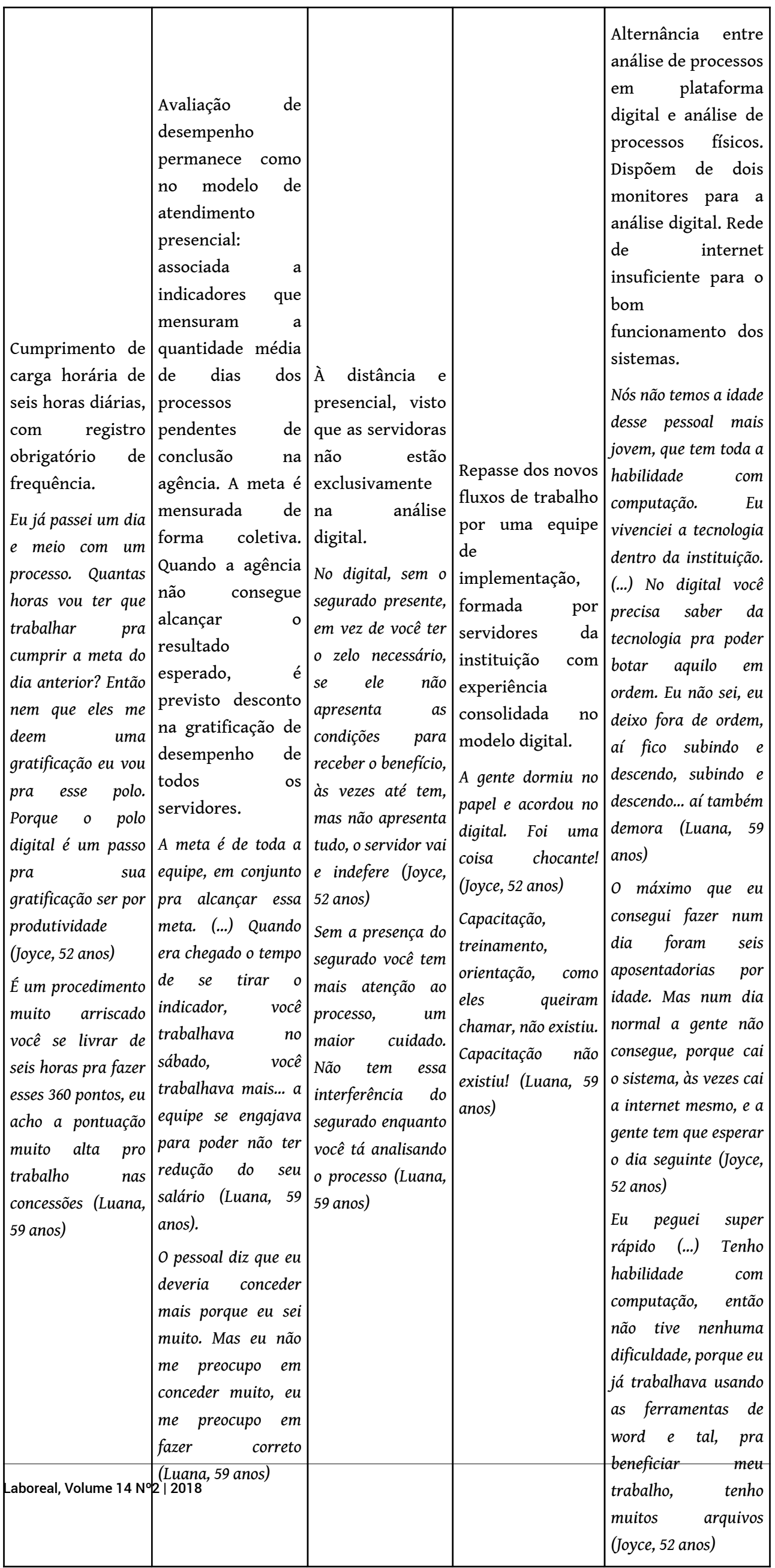


Quadro II: Estratégias de regulação e modos operatórios utilizados pelos servidores da APS

\begin{tabular}{|c|c|c|c|c|}
\hline Trabalhador(a) & Idade & $\begin{array}{l}\text { Antiguidade } \\
\text { no INSS }\end{array}$ & $\begin{array}{l}\text { Estratégias e modos } \\
\text { operatórios utilizados }\end{array}$ & Extratos de discursos \\
\hline Luana & $\begin{array}{l}59 \\
\text { anos }\end{array}$ & 35 anos & 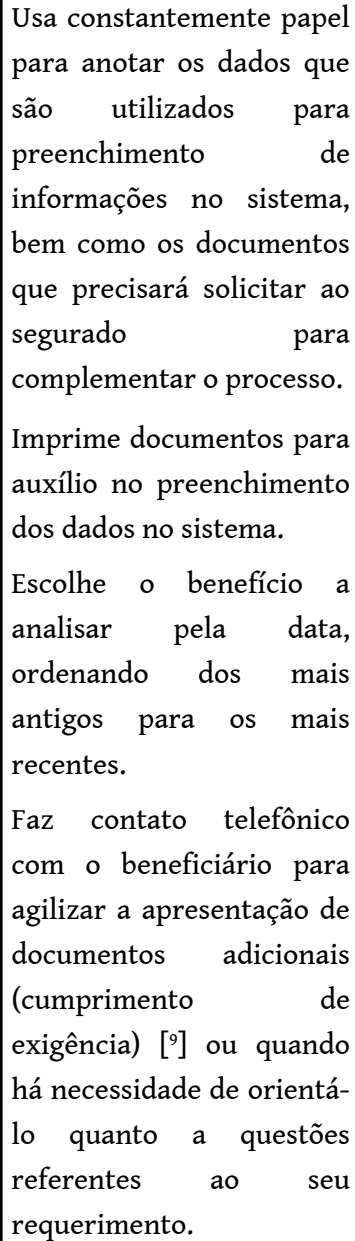 & $\begin{array}{l}\text { Você começa anotando os dados } \\
\text { do segurado no papel, aí facilita. } \\
\text { Eu vou tirar o extrato dos } \\
\text { salários de contribuição, vou } \\
\text { imprimir primeiro pra poder } \\
\text { jogar aqui depois, pra eu não tá } \\
\text { olhando aqui, porque aqui ele sai } \\
\text { pequeninho. Como eu vou ficar lá } \\
\text { e cá [alternando a atenção entre } \\
\text { as duas telas] então eu prefiro } \\
\text { tirar a impressão. } \\
\text { Você vai pela ordem do mais } \\
\text { antigo, sempre por aí, o processo } \\
\text { mais antigo primeiro. } \\
\text { No digital o pedido de exigência } \\
\text { vai automático pro segurado, } \\
\text { mas mesmo assim você deve ligar } \\
\text { pro segurado e pedir que ele } \\
\text { agilize aquela exigência. }\end{array}$ \\
\hline
\end{tabular}




\begin{tabular}{|c|c|c|c|c|}
\hline Joyce & $\begin{array}{l}52 \\
\text { anos }\end{array}$ & 33 anos & 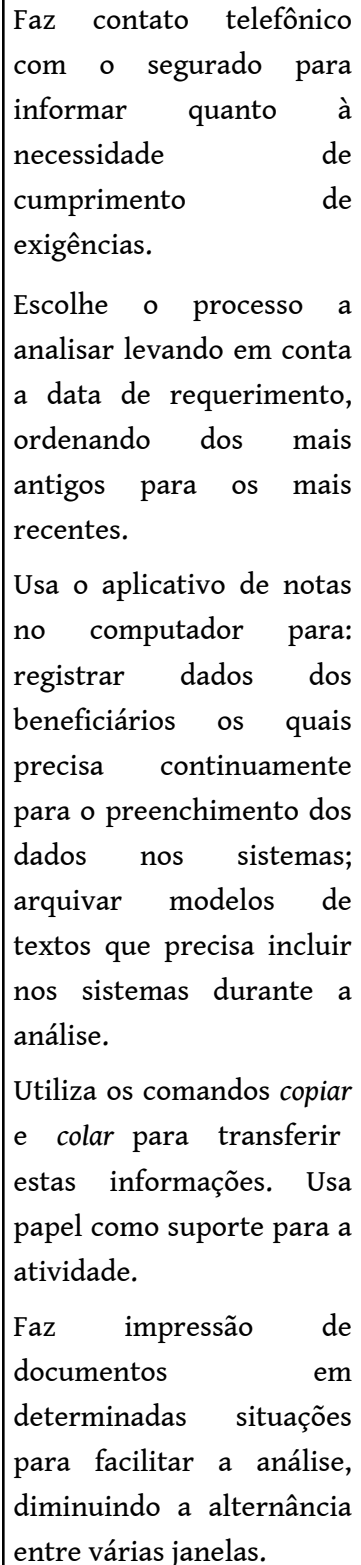 & $\begin{array}{l}\text { } \\
\\
\\
\text { Quando tem exigência, se a } \\
\text { pessoa tiver email cai } \\
\text { automaticamente. Só que as } \\
\text { pessoas não são de acompanhar } \\
\text { diariamente. Então você pode } \\
\text { ligar, e se você não conseguir } \\
\text { falar ao telefone, você envia uma } \\
\text { carta. Você deve ter esse zelo pelo } \\
\text { segurado, até porque isto } \\
\text { também vai tornar seu trabalho } \\
\text { mais eficiente, você vai ter mais } \\
\text { celeridade. } \\
\text { Na lista de tarefas do GET [10]vocêe } \\
\text { vai priorizar as vermelhinhas, as } \\
\text { atrasadas. Você não vai por } \\
\text { espécie, vai por data. } \\
\text { Você pode usar essas notas } \\
\text { porque aí é só copiar e colar, pra } \\
\text { não ter que estar escrevendo as } \\
\text { mesmas coisas... }\end{array}$ \\
\hline
\end{tabular}

4.2.2. Atividade de análise no polo digital A: 'eu posso optar por trabalhar à tarde, à noite, final de semana...'

O polo de análise em questão situa-se em outra cidade da região Nordeste, onde se operacionalizou etapa piloto da proposta de digitalização do atendimento. A experiência desta unidade foi referência para a expansão do projeto. Exercem suas atividades neste polo, servidores cuja lotação de origem varia entre diferentes agências da capital e do interior do estado. No polo, eles analisam requerimentos tanto de suas unidades de lotação quanto de outras, e estão submetidos à cobrança de pontuação mínima mensal, com flexibilidade com relação ao horário e local de trabalho. 


\begin{tabular}{|c|c|c|c|c|}
\hline $\begin{array}{l}\text { Horário } \\
\text { trabalho }\end{array}$ & $\begin{array}{l}\text { Metas e controle de } \\
\text { produção }\end{array}$ & o & $\begin{array}{l}\text { Formação para e } \\
\text { no trabalho }\end{array}$ & $\begin{array}{l}\text { Digitalização e } \\
\text { uso das } \\
\text { ferramentas } \\
\text { tecnológicas }\end{array}$ \\
\hline 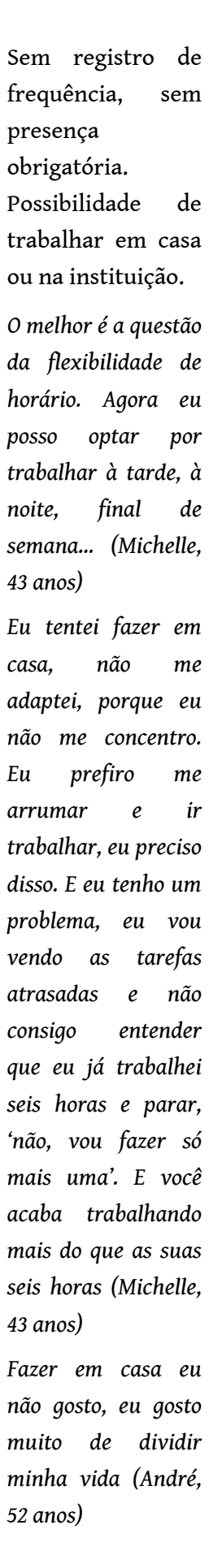 & 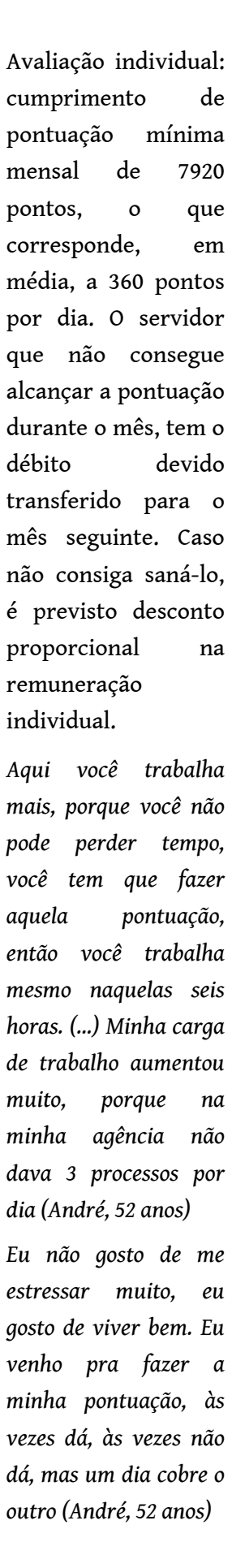 & $\begin{array}{l}\text { Somente à } \\
\text { distância. } \\
\text { o processo sem } \\
\text { segurado ali na } \\
\text { frente melhorou } \\
\text { muito o nível de } \\
\text { estresse. Mas o } \\
\text { fato de não ser } \\
\text { presencial não } \\
\text { tira } \\
\text { necessidade de } \\
\text { contato com o } \\
\text { segurado, senão } \\
\text { a gente começa a } \\
\text { fazer processos } \\
\text { mal feitos, e no } \\
\text { modo automático } \\
\text { (Michelle, } 43 \\
\text { anos) } \\
\text { Quando você não } \\
\text { sabe do processo, } \\
\text { você não tá ali } \\
\text { cara a cara com } \\
\text { o segurado. Você } \\
\text { pode gastar mais } \\
\text { tempo, e não tem } \\
\text { aquela ansiedade } \\
\text { porque a pessoa } \\
\text { tá ali olhando } \\
\text { (André, 52 anos) }\end{array}$ & 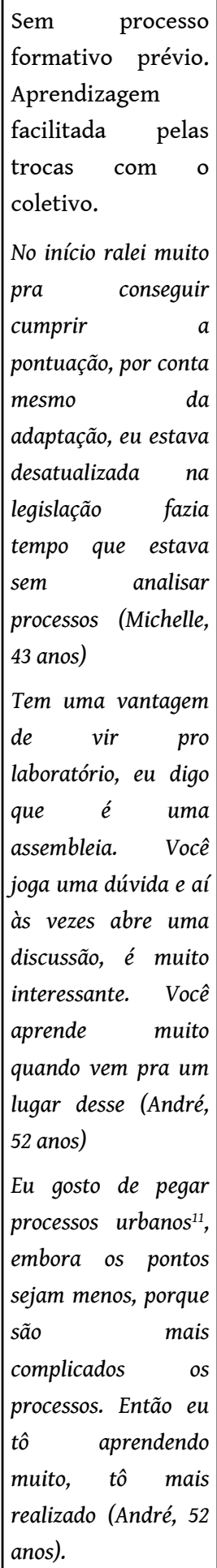 & $\begin{array}{l}\text { Dispõem de dois } \\
\text { monitores. Rede } \\
\text { de internet } \\
\text { suficiente. } \\
\text { Eu prefiro o digital. } \\
\text { Não é porque } \\
\text { trabalha mais nem } \\
\text { menos, é porque é } \\
\text { mais tranquilo, } \\
\text { apesar que eu } \\
\text { gosto de atender, } \\
\text { eu gosto de } \\
\text { contato, mas ainda } \\
\text { assim eu prefiro o } \\
\text { digital (André, } 52 \\
\text { anos) } \\
\text { o GET é muito } \\
\text { tranquilo, e olhe } \\
\text { que eu não sou } \\
\text { dessa geração nova } \\
\text { de internet, mas } \\
\text { não tenho } \\
\text { dificuldade } \\
\text { (Michelle, } 43 \text { anos) } \\
\text { Aqui a gente tem } \\
\text { as condições ideais: } \\
\text { anternet }\end{array}$ \\
\hline
\end{tabular}


Quadro IV: Estratégias de regulação e modos operatórios utilizados pelos servidores do Polo A

\begin{tabular}{|c|c|c|c|c|}
\hline Trabalhador(a) & Idade & $\begin{array}{l}\text { Antiguidade } \\
\text { no INSS }\end{array}$ & $\begin{array}{l}\text { Estratégias e modos } \\
\text { operatórios utilizados }\end{array}$ & Extratos de discursos \\
\hline André & $\begin{array}{l}52 \\
\text { anos }\end{array}$ & 06 anos & 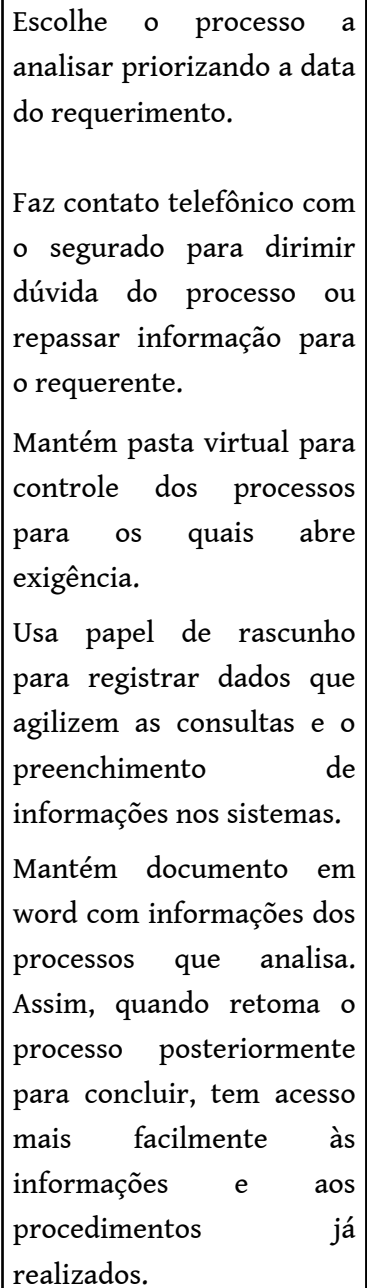 & $\begin{array}{l}\text { Você sempre vai escolher os mais } \\
\text { atrasados, pode ser o mais difícil } \\
\text { do mundo, mas você fica nele. } \\
\text { Porque é desleal você não olhar o } \\
\text { prazo. Independente do tipo de } \\
\text { benefício, eu pego aquele e fico } \\
\text { até terminar. } \\
\text { Eu costumo telefonar. Sei nem se } \\
\text { é certo ou errado, mas eu faço. } \\
\text { Eu uso uma pasta que quem vê } \\
\text { pensa que é até coisa de louco. } \\
\text { Eu boto um T na frente, pra dizer } \\
\text { que é telegrama, eu coloco, por } \\
\text { exemplo, o0oT, é telegrama, o0oE, } \\
\text { é exigência, que é pra ficar um } \\
\text { atrás do outro, saio separando lá. } \\
\text { Você vai usar um papel e uma } \\
\text { caneta. A primeira coisa é anotar } \\
\text { a DER [data de entrada do } \\
\text { requerimento]. Aí digamos que } \\
\text { seja uma pensão, você vai } \\
\text { olhando, bota o óbito, bota o } \\
\text { número da folha que tá, que é } \\
\text { pra você já clicar na folha certa, } \\
\text { pra não ficar subindo e descendo } \\
\text { o papel, principalmente quando } \\
\text { o processo é grande. }\end{array}$ \\
\hline
\end{tabular}




\begin{tabular}{|c|c|c|c|c|}
\hline Michelle & $\begin{array}{l}43 \\
\text { anos }\end{array}$ & 14 anos & $\begin{array}{l}\text { Escolhe o processo a } \\
\text { analisar a partir do tipo de } \\
\text { benefício e da data de } \\
\text { requerimento. } \\
\text { Organiza seu tempo de } \\
\text { forma que um dia da } \\
\text { semana seja dedicado a } \\
\text { acompanhar os processos } \\
\text { em exigência. } \\
\text { Faz contato telefônico com } \\
\text { o segurado em situações de } \\
\text { necessidade } \\
\text { cumprimento de exigência } \\
\text { ou de esclarecimento de } \\
\text { informações. } \\
\text { Usa papel para registro de } \\
\text { informações que precisará } \\
\text { para o preenchimento nos } \\
\text { sistemas. }\end{array}$ & $\begin{array}{l}\text { Quando você chega, já escolhe o } \\
\text { que vai fazer, porque é o mesmo } \\
\text { processo, a mesma lógica de } \\
\text { raciocínio. Aí você procura os } \\
\text { que estão mais atrasados } \\
\text { daquela espécie. } \\
\text { Geralmente na sexta você tira } \\
\text { pra olhar exigências que tem, } \\
\text { porque se você não acompanha, } \\
\text { perde o controle. } \\
\text { Se você viu que a pessoa não teve } \\
\text { ciência, você liga, manda } \\
\text { telegrama, chama pra conversar. } \\
\text { Se tá faltando as contribuições, } \\
\text { eu vou passar o processo } \\
\text { sabendo que vai influenciar no } \\
\text { valor do benefício? Não vou! Esse } \\
\text { feedback com o segurado não } \\
\text { pode ser perdido. } \\
\text { Você precisa usar papel só pra } \\
\text { fazer uma anotação, ali no } \\
\text { momento, alguma coisa que vocêe } \\
\text { tenha dúvida... pronto, você vai } \\
\text { anotar aqui que a renda foi } \\
\text { tanto, quando você for preencher } \\
\text { no sistema você vai se lembrar } \\
\text { desse valor. }\end{array}$ \\
\hline
\end{tabular}

\subsubsection{Atividade de análise no polo digital B: 'há um esforço nosso em mostrar que o projeto é viável'}

A última situação de trabalho aqui retratada caracteriza-se por dupla exigência com relação ao controle de produção. A despeito das normativas nacionais que preveem uma pontuação mensal de 7920 pontos para os servidores nos polos de análise, a gestão local da unidade a qual são vinculados os participantes em exercício neste polo exige também a análise de oito processos diários.

O polo B localiza-se em uma capital e reúne servidores de diferentes agências distribuídas pela capital e interior do estado, que respondem por demandas de sua unidade de lotação e de outras agências da região. Os servidores incluídos no estudo têm lotação original em uma APS do interior.

Quadro V: Vivência de mudança entre os servidores do Polo B

\begin{tabular}{|l|l|l|l|l|}
\hline $\begin{array}{l}\text { Horário de } \\
\text { trabalho }\end{array}$ & $\begin{array}{l}\text { Metas e controle de } \\
\text { produção }\end{array}$ & $\begin{array}{l}\text { Relação com o } \\
\text { usuário }\end{array}$ & $\begin{array}{l}\text { Formação para e no } \\
\text { trabalho }\end{array}$ & $\begin{array}{l}\text { Digitalização e uso } \\
\text { das ferramentas } \\
\text { tecnológicas }\end{array}$ \\
\hline
\end{tabular}




\begin{tabular}{|c|c|c|c|c|}
\hline $\begin{array}{l}\text { Sem registro } \\
\text { de } \\
\text { frequência, } \\
\text { mas com } \\
\text { presença } \\
\text { obrigatória. } \\
\text { A gente tem } \\
\text { que vir todos } \\
\text { os dias, mas } \\
\text { quando a } \\
\text { gente conclui } \\
\text { os oito } \\
\text { benefícios a } \\
\text { gente já pode } \\
\text { sair (Felipe, } 31 \\
\text { anos) }\end{array}$ & 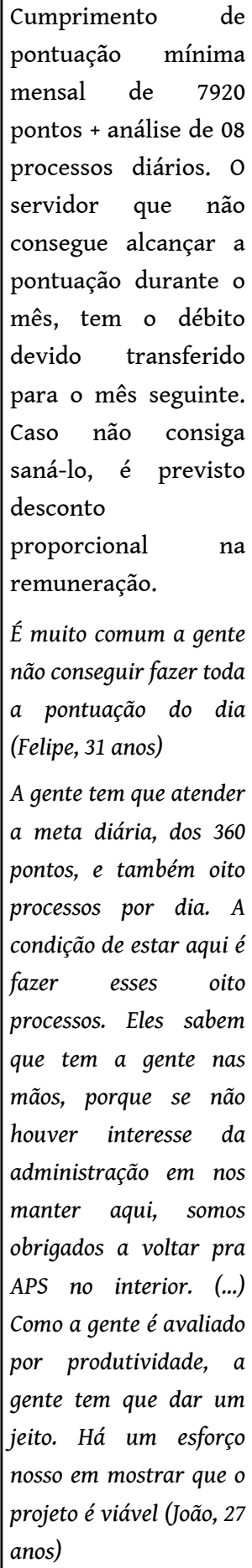 & $\begin{array}{l}\text { Somente à } \\
\text { distância. } \\
\text { Hoje eu não } \\
\text { preciso mais ter } \\
\text { contato com o } \\
\text { público, tenho } \\
\text { menos } \\
\text { interrupções. } \\
\text { Então eu consigo } \\
\text { realmente me } \\
\text { concentrar no } \\
\text { que eu devo } \\
\text { fazer que é } \\
\text { analisar um } \\
\text { processo (João, } \\
27 \text { anos). }\end{array}$ & 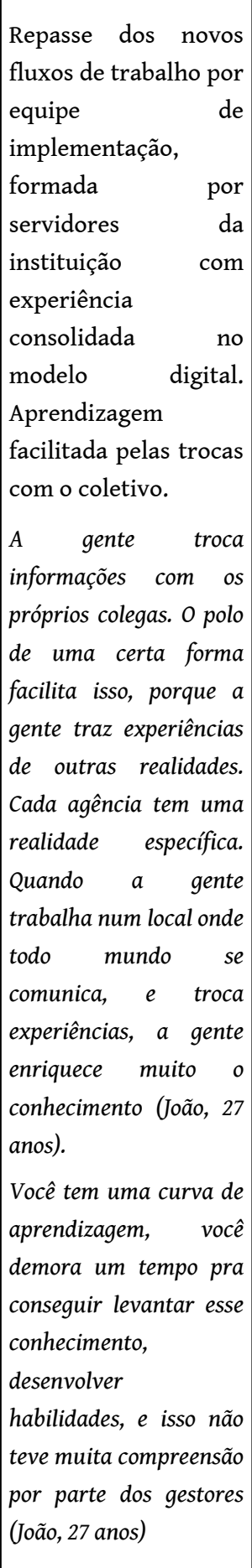 & 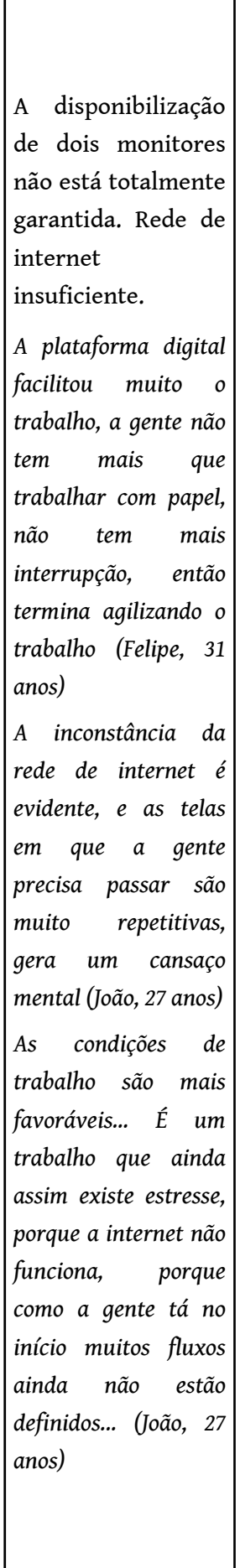 \\
\hline
\end{tabular}

Quadro VI: Estratégias de regulação e modos operatórios utilizados pelos servidores do Polo B

\begin{tabular}{|l|l|l|l|l|}
\hline Trabalhador(a) & Idade & $\begin{array}{l}\text { Antiguidade } \\
\text { no INSS }\end{array}$ & $\begin{array}{l}\text { Estratégias e modos } \\
\text { operatórios utilizados }\end{array}$ & Extratos de discursos \\
\hline
\end{tabular}




\begin{tabular}{|c|c|c|c|c|}
\hline João & $\begin{array}{l}27 \\
\text { anos }\end{array}$ & 06 anos & $\begin{array}{l}\text { Realiza dois ou mais } \\
\text { procedimentos } \\
\text { simultaneamente, } \\
\text { aproveitando o momento } \\
\text { em que os sistemas estão } \\
\text { carregandor as } \\
\text { informações. } \\
\text { Salva em bloco de notas } \\
\text { vários modelos de textos } \\
\text { para os diferentes } \\
\text { despachos que utiliza. Usa } \\
\text { comandos 'copiar' } \\
\text { 'colar'. } \\
\text { Seleciona os benefícios } \\
\text { pela espécie, priorizando } \\
\text { analisar seguidamente o } \\
\text { mesmo tipo, para manter } \\
\text { a lógica de raciocínio. } \\
\text { Alterna benefícios mais } \\
\text { complexos com os mais } \\
\text { simples, considerando o } \\
\text { esforço cognitivo exigido. } \\
\text { Usa rascunho em papel } \\
\text { para facilitar em casos } \\
\text { específicos } \\
\text { preenchimento } \\
\text { informações nos sistemas. }\end{array}$ & $\begin{array}{l}\text { Enquanto o processo tá } \\
\text { carregando, você já pode ir } \\
\text { alimentando as informações. Você } \\
\text { tem realmente que otimizar o } \\
\text { tempo. } \\
\text { Você tenta estabelecer alguns } \\
\text { critérios, um dia você pega um } \\
\text { tipo de benefício, no dia seguinte } \\
\text { pega outro, porque você vai } \\
\text { conseguir criar um fluxo mais } \\
\text { rápido. Mas nem sempre isso } \\
\text { procede porque existe também } \\
\text { uma limitação mental. Tem } \\
\text { processos que demandam maior } \\
\text { esforço de raciocínio então você } \\
\text { não consegue fazer todos num dia } \\
\text { só, a cabeça fica muito parada, aí } \\
\text { você pode alternar com processos } \\
\text { mais simples. } \\
\text { Quase nada a gente imprime } \\
\text { mais. Você pode fazer alguns } \\
\text { rascunhos, quando você for fazer } \\
\text { algum acerto de vínculo, e precisa } \\
\text { escrever que de período tal a } \\
\text { período tal não teve } \\
\text { remuneração, você pega um } \\
\text { rascunho e ali mesmo escreve, } \\
\text { pra facilitar. }\end{array}$ \\
\hline
\end{tabular}




\begin{tabular}{|c|c|c|c|c|}
\hline Felipe & \begin{tabular}{|l}
31 \\
anos
\end{tabular} & 06 anos & 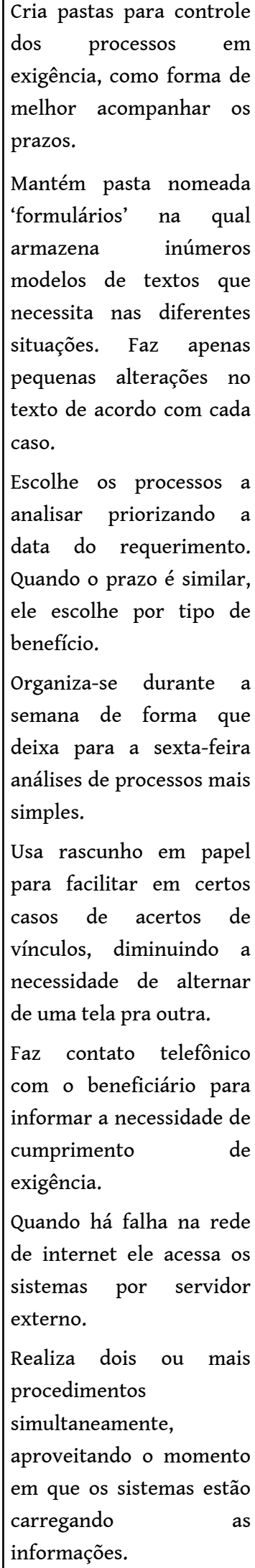 & $\begin{array}{l}\text { } \\
\text { lato } \\
\text { Quando eu faço uma exigência, } \\
\text { gosto de ligar pro segurado pra } \\
\text { ele não ter que esperar, eu não sei } \\
\text { se ele vai visualizar aquilo em } 30 \\
\text { dias. Então você liga e avisa pra } \\
\text { agilizar né? } \\
\text { Aqui já pela prática... no começo } \\
\text { eu anexava os documentos um a } \\
\text { um, como eu verifiquei que } \\
\text { sempre que eu fazia uma } \\
\text { tentativa de anexar o sistema } \\
\text { poderia cair, eu deixo pra anexar } \\
\text { textos quando eu vou concluir a } \\
\text { gente pensa que é besteira, mas } \\
\text { esses macetes ao longo do dia } \\
\text { todo, em diversos benefícios dá } \\
\text { quase uma hora de economia. }\end{array}$ \\
\hline
\end{tabular}




\section{Discussão}

\subsection{Condições de implementação do novo modelo de atendimento e tensões vivenciadas pelos trabalhadores}

47 A articulação entre a perspectiva institucional sobre o novo modelo de atendimento e a análise das situações concretas de trabalho permite identificar distância significativa entre aquilo que preveem os conceptores e o que tem sido concretizado nas diferentes unidades do INSS.

48 As condições de gerenciamento locais têm dado contornos diferenciados à implementação do projeto INSS Digital. Observa-se heterogeneidade nas formas de controle de produção, que diverge entre as unidades e em relação às normas previstas no projeto; e condições diferenciadas de recursos disponibilizados para garantir a realização do trabalho (como a qualidade da rede de internet), a apropriação e a integração das novas ferramentas à atividade (tais como a existência e o tipo de formação para o trabalho).

Diante dos imprevistos e variabilidades do contexto real, os servidores precisam desenvolver estratégias para mediar algumas tensões, as quais colocam em questão, especialmente: as metas e modalidades de controle de produção, a formação para o trabalho, e a relação com o usuário.

\subsubsection{Quanto às metas de produtividade e as modalidades de controle de produção}

50 Apresenta-se como tensão vivenciada pelos servidores na transição para o atendimento digital a concepção das metas de produtividade individuais. Estas metas foram elaboradas com base nos tempos máximos que deveriam ser cumpridos pelos trabalhadores para atendimento de cada tipo de serviço no modelo presencial. No entanto, este tempo máximo já era considerado insuficiente pelos trabalhadores das agências (APS), que se engajavam coletivamente na construção de estratégias para darem conta das regras prescritas.

51 A análise dos discursos das servidoras da APS permitiu evidenciar um trabalho de reorganização da tarefa pelo coletivo profissional, uma recriação da organização do trabalho pelo trabalho de organização do coletivo (Caroly \& Clot, 2004).

52 Frente à pressão temporal a que estavam sujeitos os servidores durante o atendimento aos beneficiários, e diante do risco de sofrerem desconto em sua gratificação, o coletivo construía estratégias de regulação para conseguir alcançar os resultados de desempenho e melhor proteger a saúde dos trabalhadores. À época de aferição dos resultados, por exemplo, os servidores intensificavam o trabalho para concluir os processos pendentes de conclusão na agência; e/ou ampliavam a oferta de vagas para a entrada de novos requerimentos de benefícios. Assim, na semana de aferição da meta, a quantidade de novos processos em aberto compensava aqueles que estavam pendentes de conclusão. Isto forçava para baixo a média da quantidade de dias dos processos inconclusos, atrelada à gratificação de desempenho.

53 A inadequação das metas de produtividade é questão também nos discursos dos servidores em exercício nos polos digitais. A impossibilidade de dar conta da pontuação diária aparece como uma realidade concreta, não restrita a situações ocasionais. A 
fragilidade das metas está em não conseguirem ser representativas da complexidade da atividade de análise de benefícios previdenciários, das variabilidades das situações encontradas em cada requerimento, e da quantidade de procedimentos que precisam ser realizados para a inclusão das informações nos sistemas técnicos.

Quanto às modalidades de controle de produção, estratégias de gerenciamento local acabam por sujeitar os trabalhadores do polo digital B a um contexto de restrições muito mais significativas. Justificando-se pela quantidade de processos pendentes de análise e pela necessidade de apresentar resultados quanto à celeridade do atendimento no INSS, a gestão impõe para os servidores a cobrança adicional de realização de oito análises diárias.

55 A exigência acrescida não é acompanhada de nenhum prêmio de produtividade. Pelo contrário, para os servidores participantes deste estudo, o alcance da meta estabelecida localmente, para além do cumprimento dos 7920 pontos mensais, é condição para a permanência no polo digital. Isto acaba por fragilizar os trabalhadores que, mobilizados pelo interesse de permanecer no polo (a fim de reduzirem os deslocamentos de casa para o trabalho), sujeitam-se a estas situações de hipersolicitação, colocando em risco a preservação de sua saúde.

\subsubsection{Quanto à formação para (e no) trabalho}

56 Com relação aos recursos para a apropriação das novas tecnologias, destaca-se a falta de formação para o trabalho a partir da implementação da digitalização do atendimento, ou sua inadequação com relação às necessidades concretas dos trabalhadores. Esta tensão é evidenciada especialmente na vivência das servidoras da APS, que referem a transição abrupta para a nova forma de organização do trabalho. Mas também está presente nos discursos dos demais trabalhadores, quando comentam sobre a maior dificuldade para alcançar os níveis de desempenho no início de seu exercício nos polos digitais.

57 A forma como o sujeito constrói a relação com os artefatos e os esquemas de utilização que desenvolvem são fundamentais para determinar em que medida eles conseguem transformar estes artefatos em instrumentos que efetivamente façam sentido para a atividade (Rabardel, 1995). A apropriação envolve a reconstrução das ferramentas pelos sujeitos, de forma que elas sejam não apenas recursos para facilitar o trabalho, mas se consolidem como instrumentos de desenvolvimento da atividade, de novas formas de fazer para alcançar os objetivos de desempenho - tanto aqueles que são impostos ao trabalhador como os que ele próprio determina para si (Bobillier Chaumon \& Clot, 2016).

O ponto de vista assumido face ao novo modelo de trabalho, retratado nos discursos dos trabalhadores nas três situações concretas, é resultante em grande medida desta avaliação individual sobre a possibilidade de apropriação e integração das ferramentas, mais ou menos facilitadas pelas condições de formação para o trabalho.

59 Os relatos deixam claro que as ações de formação, quando existiram, foram insuficientes para a apropriação dos novos sistemas, ferramentas e fluxos de trabalho. Sobre este assunto, Santos e Lacomblez (2016) discutem que frequentemente as ações de formação profissional não são proveitosas para os trabalhadores, nem adequadas às realidades de trabalho com que se confrontam. Em parte, porque são conduzidas na urgência e determinadas por imperativos que definem os novos modos de desempenhar 
uma função, aos quais é esperado que os trabalhadores se adaptem. Isto acaba por impedir a completa apropriação das ferramentas, implicando em dificuldades no desenvolvimento de novos usos e sentidos para elas, limitando o potencial de renovação da atividade. Ao negligenciar os processos formativos aquando da introdução de novas tecnologias ao trabalho, corre-se o risco de produzir movimentos de exclusão de trabalhadores que não possuem domínio da informática.

60 Nos polos de análise, as deficiências na formação para o trabalho acabam por ser em parte compensadas pelo intercâmbio de conhecimentos e práticas que se desenvolvem entre os trabalhadores. Evidenciou-se, nestes contextos, um processo de formação no trabalho, orientado para o preenchimento de lacunas na experiência de alguns trabalhadores com relação ao uso das ferramentas informáticas.

\subsubsection{Quanto à relação com o usuário}

61 A construção de outra relação com o usuário a partir do atendimento digital coloca em questionamento a qualidade da atividade de análise de benefícios previdenciários. Se, por um lado, o atendimento à distância é avaliado positivamente por permitir maior concentração do trabalhador para a realização de um trabalho bem feito; por outro, a presença do beneficiário no momento da análise possibilitava que possíveis dúvidas dos analisadores pudessem ser imediatamente dirimidas, além de figurar como importante oportunidade de repasse de informações e esclarecimentos para o usuário.

o que questionam alguns dos trabalhadores entrevistados é se o atendimento à distância, aliado ao modelo de avaliação por produtividade individual, não acabará por resultar em um número maior de benefícios indeferidos, muito mais por falta de dados que fundamentem a tomada de decisão, do que propriamente pela ausência de condições para a consecução do direito. Isto porque, para garantir a meta mensal de quantidade de processos analisados, os trabalhadores podem optar por não formalizar pedido de exigência, tendo em vista que um processo pendente de conclusão garante apenas metade da pontuação prevista.

\subsection{Margens de Manobra e Estratégias de Regulação}

63 A análise da atividade revelou distintas formas de gestão do trabalho e esquemas de utilização das ferramentas tecnológicas. Se, por um lado, estas diferenças refletem as singularidades dos sujeitos participantes, evidenciam, também, as implicações das condições de implementação do novo modelo de atendimento nas três situações.

Os esquemas de utilização das ferramentas e as estratégias desenvolvidas pelos trabalhadores variam, especialmente, segundo os níveis de exigência e intensificação do trabalho; e os níveis de apropriação das novas tecnologias. Ademais, identificou-se como estratégia comum a manutenção de contato pessoal com o usuário, associada tanto à percepção de qualidade do atendimento quanto à possibilidade de dar mais celeridade ao processo de trabalho.

\subsubsection{Quanto aos níveis de exigência e intensificação do trabalho}

65 As diferenças nas modalidades de controle de produção e avaliação do trabalho figuram entre os principais fatores que influenciam os esquemas de utilização e as estratégias elaboradas pelos trabalhadores. Enquanto no modelo de atendimento presencial havia 
uma margem de manobra construída coletivamente, expressa no trabalho de reorganização do coletivo profissional; o que se percebe no atendimento digital é que esta margem se expressa como uma construção individual, face à necessidade de dar conta de exigências que recaem agora, fundamentalmente, sobre o indivíduo, em situação isolada do coletivo de trabalho.

Observa-se, principalmente, diferenças entre as estratégias e os usos das ferramentas tecnológicas elaborados pelas servidoras vinculadas à APS (e que ainda não respondem a metas de produtividade individuais), daqueles desenvolvidos pelos trabalhadores do polo digital B. Para estes últimos, tendo em vista a intensificação do trabalho (resultante do alto nível de exigência aliado à insuficiência dos recursos), as estratégias mobilizadas parecem ser orientadas, fundamentalmente, para a otimização do tempo de operacionalização das tarefas.

67 Assim, os servidores do polo digital B desenvolvem modos operatórios - que se reconstroem e se atualizam permanentemente na prática de uso das ferramentas - na tentativa de responder às restrições que se impõem no contexto de trabalho e garantir o desempenho esperado, ao mesmo tempo em que tentam proteger sua saúde. Dentre estas restrições, destacam-se a insuficiência da rede de internet; e inadequações próprias dos sistemas técnicos, percebidos como 'repetitivos', 'cansativos', que não favorecem a agilidade esperada.

68 Acrescenta-se a isto o fato de que os trabalhadores do polo B nem sempre podiam contar com dois monitores para a análise dos processos. Tendo em vista a quantidade de sistemas e aplicativos acessados para a atividade de análise, o uso de apenas uma tela representa prejuízo considerável para a atividade, implicando em extensão do tempo de análise e exigência mental ainda maior pela constante alternância entre várias 'janelas'.

69 Estes diferentes modos operatórios podem ser exemplificados a partir dos discursos dos trabalhadores João (27 anos) e Felipe (31 anos): (1) análise seguida de processos de um mesmo tipo, a fim de otimizar o fluxo de trabalho pela manutenção de uma lógica cognitiva uniforme; (2) elaboração de textos modelo para a inserção de informações nos sistemas e preenchimento de documentos (uso constante dos comandos 'copiar e colar'); (3) realização de duas ou mais operações simultaneamente, aproveitando a demora no tempo de resposta dos sistemas; (4) acesso aos sistemas corporativos por servidor externo quando há falha na rede de intranet; (5) alternância entre a análise de processos mais complexos com aqueles avaliados como mais simples, como tentativa de aliviar a carga mental associada à atividade.

70 Para as servidoras vinculadas à APS, por outro lado, a restrição temporal não se coloca tão fortemente como questão, considerando que não têm sido cobradas por uma pontuação mínima diária. Entre elas não se identificou a operacionalização de duas ou mais tarefas ao mesmo tempo, nem outras tentativas de contornar as dificuldades na rede de internet. Diante da demora no tempo de resposta dos sistemas informáticos, por exemplo, as trabalhadoras, na maior parte das vezes, apenas aguardavam.

71 Quanto aos servidores do polo digital A, evidenciou-se uma margem de manobra mais ampla para a elaboração de modos operatórios capazes de favorecer o desenvolvimento da atividade. Esta margem de manobra parece ser possibilitada, dentre outros fatores, pela exigência de produtividade que recai sobre estes trabalhadores (restrita à 
cobrança de pontuação mensal de 7920 pontos); bem como pelos recursos técnicos oferecidos (rede de internet adequada; disponibilização de dois monitores).

Destaca-se a experiência do servidor André (52 anos) quanto à construção de um espaço de regulação que lhe permite jogar com os objetivos e recursos disponibilizados, ampliando seu raio de ação e possibilitando a criação de novos objetivos para si. A análise de benefícios é acrescida de significados quando passa a representar, para ele, oportunidade de aprendizagem e desenvolvimento de competências. Esta margem de manobra lhe possibilita, por exemplo, assumir o risco de priorizar análise de benefícios de maior nível de complexidade, mesmo que isto signifique ter que 'se desgastar mais' para alcançar a pontuação prescrita.

Em situação de menor nível de exigência e menos restrições, os trabalhadores do polo $\mathrm{A}$ conseguem gerir com mais flexibilidade o tempo de trabalho e a quantidade de benefícios analisados diariamente. Isto permite a concretização de um rico espaço de trocas e aprendizagem, evidenciado pelas constantes interações entre os servidores identificadas durante a observação da atividade. As discussões giravam em torno da interpretação da legislação, de dúvidas na interação com os sistemas corporativos, de maneiras de proceder e de macetes para melhor organizar o trabalho.

Os esquemas de utilização das ferramentas desenvolvidos por estes trabalhadores acabam por se voltar mais para a organização de seu processo de trabalho do que propriamente para a otimização e redução do tempo de análise, como pôde ser observado entre os servidores do polo B.

\subsubsection{Quanto aos níveis de apropriação das novas tecnologias}

Foi possível observar diferentes esquemas de utilização das ferramentas informáticas a depender da familiaridade dos trabalhadores com as novas tecnologias e dos recursos disponíveis para sua apropriação.

Entre as trabalhadoras vinculadas à APS, observou-se um uso mais restrito das funcionalidades das diferentes aplicações e ferramentas informáticas do que quando comparado aos demais servidores, com uso muito mais constante do papel como recurso para a realização do trabalho.

Dentre os servidores dos polos de análise, por outro lado, observou-se: o manejo de pastas virtuais para armazenamento de informações sobre os processos; controle virtual de processos pendentes de conclusão; arquivamento de orientações normativas e legislações pertinentes; elaboração de planilha para acompanhamento da produtividade mensal. Entre estes trabalhadores, nota-se uma melhor apropriação das ferramentas tecnológicas. Se por vezes há necessidade de uso do papel, isto pode ser encarado como manifestação de um saber-fazer que permite melhorar o desempenho e lidar simultaneamente com várias tarefas. Esta estratégia evidencia limitações das ferramentas tecnológicas, como a digitalização que dificulta a leitura dos documentos, e a necessidade de alternar entre várias 'janelas' ao mesmo tempo, que pode implicar em aumento da carga cognitiva da atividade.

Maior familiaridade com a tecnologia foi perceptível entre os servidores João (27 anos) e Felipe (31 anos). Ambos exibiram muita agilidade na interação com as ferramentas, com a realização de grande número de operações em pequeno intervalo de tempo. 0 mesmo não foi evidenciado no caso das trabalhadoras Luana (59 anos) e Joyce (52 anos), resultando em tempos significativamente mais longos de duração das análises. À pouca 
familiaridade com as tecnologias, soma-se a ausência de formação adequada para o trabalho, que possibilitasse uma melhor apropriação destes recursos pelas trabalhadoras.

79 A propósito desta questão, Pavageau, et al. (2007) discutem que, se a interação com a tecnologia tende a ser vivenciada com mais dificuldade pelas pessoas de mais idade, o processo de aprendizagem das ferramentas não parece estar associado à faixa etária. Os autores enfatizam a deficiência nos processos de formação para o trabalho, bem como a falta de suporte do coletivo profissional para possibilitar a aprendizagem em situação, como elementos mais relevantes para explicar a dificuldade de apropriação das ferramentas tecnológicas, independentemente da idade do trabalhador.

80 A maior dificuldade na apropriação das ferramentas pode estar associada, também, ao fato de as servidoras, com mais tempo de serviço, terem construído suas competências em um contexto organizacional muito mais estável (Pavageau, et al., 2007). Como relata Luana, sua relação com o universo digital teve início no próprio ambiente organizacional, face à necessidade de se adaptar às evoluções tecnológicas. Apesar de a servidora já interagir com plataformas digitais para a análise de benefícios, estas eram de interface mais simples e não exigiam o domínio de esquemas de uso básicos, tais como conhecer teclas de comando para salvar documentos, copiar, colar, ou alternar entre 'janelas'.

81 Se a escolha das servidoras por permanecerem vinculadas à APS pode ser encarada pela organização como uma resistência às mudanças nos processos de trabalho; ela é, para nós, entendida na perspectiva de uma mobilização do 'corpo-si' na preservação da saúde (Durrive \& Schwartz, 2008). Como discutem Christo e Borges (2017), se compreendemos que todo trabalhador possui saberes-fazer, competências, valores e compartilham uma história coletiva, entendemos o quanto tudo isto deve ser considerado nos processos de mudança, inserindo os operadores como atores deste processo, e não meros expectadores de transformações que lhe são impostas e que podem representar obstáculos para a construção da saúde no trabalho.

\subsubsection{Quanto à manutenção de contato pessoal com o usuário}

82 Por fim, identificou-se dentre as estratégias de regulação desenvolvidas, o contorno da prescrição de impessoalidade do atendimento ao beneficiário, previsto no novo modelo de atendimento. Era esperado que a digitalização do trabalho, ao possibilitar o atendimento à distância, resultasse em mais celeridade e qualidade na prestação do serviço à sociedade.

83 No entanto, é exatamente a percepção de trabalho bem feito que faz com o que os trabalhadores continuem a manter contato pessoal com os usuários, agora por telefone, para sanar dificuldades advindas da sua ausência durante a análise do requerimento (falta de informações essenciais para o processo, ou necessidade de prestar-lhes orientações). O contato telefônico representa, também, estratégia para dar mais celeridade à conclusão do processo e garantir o acúmulo da pontuação devida.

Se o contato pessoal com o beneficiário pode ser perspectivado pela organização como incumprimento do prescrito, como uma transgressão, ele é aqui interpretado de forma positiva, como uma estratégia dos trabalhadores para garantir o cumprimento de objetivos considerados igualmente pertinentes (relacionados à qualidade do trabalho $\mathrm{e}$ ao cumprimento das metas de produtividade). 


\section{Considerações finais}

Digital estava em fase inicial de expansão, o que explica condições de implementação e formas de avaliação da produtividade tão diferenciadas entre unidades vinculadas a um mesmo órgão gestor regional. Diante disso, é importante retorno posterior ao terreno para nova investigação junto aos trabalhadores, em momento em que já estejam formalizadas todas as orientações normativas sobre o projeto e suas condições de concretização.

91 A discussão dos resultados deste estudo com os trabalhadores e os gestores, na perspectiva de envolvimento também dos representantes sindicais está prevista em 
etapa futura da investigação. Esta ação, na medida em que viabilizará espaço de debate sobre a atividade, poderá contribuir para o desenvolvimento do poder de agir dos servidores, para a renovação das práticas e reconfiguração das condições de implementação das novas tecnologias ao trabalho.

A procura por produtividade não pode ser concebida sem uma melhoria simultânea das condições de trabalho. Portanto, entende-se que são necessárias modificações nas condições oferecidas aos servidores do INSS a partir da implementação do novo modelo de atendimento, recusando que recaia unicamente sobre os próprios trabalhadores a reponsabilidade de 'transformar o uso de si em razão dos imperativos de uma lógica alheia ao seu equilíbrio' (Lacomblez \& Vasconcelos, 2009, p. 54).

\section{BIBLIOGRAFIA}

Béguin, P. (2006). Acerca de la evolución del concepto de actividad. Laboreal, 2(1), 55-61. http:// laboreal.up.pt/revista/artigo.php?id=37t45nSU5471122651:3282751

Bobillier Chaumon, M. E. (2003). Évolutions techniques et mutations du travail: émergence de nouveaux modèles d'activité. La travail humain, 66, 161-192. doi: http://dx.doi.org/10.3917/th. 662.0161

Bobillier Chaumon, M. E., \& Clot, Y. (2016). Clinique de l'usage: Les artefacts technologiques comme développement de l'activité. Activités [En ligne], 13(2), 1-7. doi: http://dx.doi.org/10.4000/ activites. 2897

Borba, L., \& Muniz, H. (2017). 'Mudando para o time': a dimensão coletiva no trabalho de atletas de vôlei de praia. Laboreal, 13(1), 56-65. http://dx.doi.org/10.15667/laborealxiii0117b

Brangier, E.; \& Hammes, S. (2007). Comment mesurer la relation humain-technologiesorganisation? Perspectives interdisciplinaires sur le travail et la santé [En ligne], 9(2), 1-16. doi: http:// dx.doi.org/10.4000/pistes.2959

Caroly, S. (2007). Les mutations du travail face aux défis technologiques: quelles incidences sur la santé? Perspectives interdisciplinaires sur le travail et la santé [En ligne], 9(2), 1-7. doi: http:// dx.doi.org/10.400/pistes.2993

Caroly S., \& Clot, Y. (2004). Du travail collectif au collectif de travail: développer des stratégies d'expérience. Formation Emploi, 88, 43-55. doi: http://dx.doi.org/10.3406/forem.2004.1737

Christo, C. de S., \& Borges, M. E. S. (2017). Reorganização do trabalho em uma agência da Previdência Social: resistência à mudança ou preservação da saúde? Saúde em Debate, 41(spe2), 104-114. doi: http://dx.doi.org/10.1590/0103-11042017s209

Clot, Y. (2010). Trabalho e poder de agir. Belo Horizonte: Fabrefactum.

Coutarel, F., Caroly, S., Vézina, N., \& Daniellou, F. (2015). Marge de manœuvre situationnelle et pouvoir d'agir: des concepts à l'intervention ergonomique. Le travail humain, 78(1), 9-29. doi: http://dx.doi.org/10.3917/th.781.0009 
Cros, F., Bobillier Chaumon, M. E., \& Cuvillier, B. (2016). Le développement de l'activité des salariés âgés: l'environnement sociotechnique comme ressource au métier d'agent de circulation. Activités, 13(2), 1-32. doi: http://dx.doi.org/10.4000/activites.2857

Cuvelier, L.; \& Caroly, S. (2011). Transformation du travail, transformation du métier: quels impacts sur la santé des opérateurs et sur l'activité collective? Perspectives interdisciplinaires sur le travail et la santé [En ligne], 13(1), 1-24. doi: http://dx.doi.org/10.4000/pistes.1732

Dubois, M.; \& Bobillier Chaumon, M. E. (2007). Développement de l'expertise des usagers via les TIC: quels enjeux pour les travailleurs des relations de services? Perspectives interdisciplinaires sur le travail et la santé [En ligne], 9(2), 1-22. doi: http://dx.doi.org/10.4000/pistes.2974

Durrive, L., \& Schwartz, Y. (2008). Glossário da Ergologia. Laboreal, 4(1), 23-38. http:// laboreal.up.pt/revista/artigo.php?id=48u560TV6582234396587;63882

Friedberg, L. (2003). The impact of technological change on older workers: evidence from data on computer use. Industrial and Labour Relations Review, 56(3), 511-29. doi: http://dx.doi.org/ $10.2307 / 3590922$

Guérin, F., Laville, A., Daniellou, F., Duraffoug, J., \& Kerguelen, A. (2001). Compreender o trabalho para transformá-lo: a prática da ergonomia. São Paulo: Editora Edgard Blucher.

Instituto Nacional do Seguro Social (2017). Projeto INSS Digital: uma nova forma de atender. Brasília, Brasil.

Lacomblez, M. (1997). A psicologia ergonómica: contribuição da psicologia do trabalho num projecto interdisciplinar na acção. Comunicação apresentada na $1^{\text {a. }}$ Conferência Internacional - Ergonomia, Segurança e Higiene Ocupacionais, Escola de Engenharia, Universidade do Minho, Guimarães, Portugal, Junho.

Lacomblez, M., \& Vasconcelos, R. (2009). Análise ergonómica da atividade, formação e transformação do trabalho: opções para um desenvolvimento durável. Laboreal, 5(1), 53-60. http://laboreal.up.pt/revista/artigo.php?id=48u560TV65822346:3347384662

Oddonne, Y., Re, A., \& Briante G. (1981). Redécouvrir l'expérience ouvrière: vers une autre psychologie du travail? Paris: Éditions Sociales.

Orlandi, E. P. (2008). Discurso e texto: formação e circulação dos sentidos. 3 ed. Campinas, SP: Pontes. Pavageau, P., Nascimento, A., \& Falzon, P. (2007). Les risques d'exclusion dans un contexte de transformation organisationnelle. Perspectives interdisciplinaires sur le travail et la santé [En ligne], 9(2), 1-21. doi: http://dx.doi.org/10.4000/pistes.2960

Picard, R. (2007). Les impacts humains des changements organisationnels autour des TIC. Perspectives interdisciplinaires sur le travail et la santé [En ligne], 9(2), 1-23. doi: http://dx.doi.org/ $10.4000 /$ pistes.2962

Rabardel, P. (1995). Les hommes et les technologies: approche cognitive des instruments contemporains. Paris: Armand Colin.

Santos, M., \& Lacomblez, M. (2016). Do artefacto ao instrumento: um modelo de avaliação das relações entre trabalho e saberes numa ação de formação. In: Wanderson Ferreira Alves, \& Maria Margarida Machado. Trabalho \& saber: questões e proposições na interface entre trabalho e formação. (pp. 13-32). Campinas: Mercado das Letras.

Teiger, C. (1993). L'approche ergonomique: du travail humain à l'activité des hommes et des femmes au travail. Education Permanente, 116(3), 71-96.

Wisner, A. (1995). Réflexions sur l'ergonomie: (1962-1995). Toulouse: Octares. 


\section{NOTAS}

1. O INSS é uma organização pública que tem como objetivo avaliar, reconhecer e conceder benefícios aos segurados da Previdência Social, garantindo uma renda ao contribuinte e sua família em situações de perda da capacidade para o trabalho. Aposentadorias, auxílio-doença, auxílio-acidente, pensão por morte, salário maternidade são benefícios operacionalizados pelo INSS.

2. 0 projeto visa à substituição progressiva do atendimento presencial aos segurados da Previdência Social, realizado até então nas unidades de atendimento (APS), pelo atendimento a distância, a partir da ampliação de serviços online e da implementação de plataforma digital para a análise de benefícios. A proposta começou a ser executada em janeiro de 2017, com projeto piloto em unidade do INSS no Nordeste do Brasil. Sua expansão tem se dado desde o início do ano de 2018.

3. A pesquisa foi previamente autorizada pelos gestores das unidades do INSS incluídas neste estudo (através de assinatura de carta de aceite), e aprovada por Comissão de Ética da Faculdade de Psicologia e Ciências da Educação da Universidade do Porto (Parecer Ref ${ }^{\mathrm{a}}$ 2018/06-2).

4. Os polos são centrais de análise de benefícios em plataforma digital, situados em prédios do INSS, onde não há atendimento presencial e que pode reunir servidores de diferentes localidades.

5. Os polos são centrais de análise de benefícios em plataforma digital, situados em prédios do INSS, onde não há atendimento presencial e que pode reunir servidores de diferentes localidades.

6. Os participantes foram orientados quanto aos procedimentos da pesquisa, $\mathrm{e}$ assinaram Termo de Consentimento Esclarecido concordando em participar. Suas identidades são resguardadas pela escolha de nomes fictícios e a não identificação de seu local de trabalho.

7. As entrevistas e verbalizações que acompanharam as observações foram registradas em áudio, após autorização dos participantes.

8. Organizações públicas, empresas privadas, ou organizações do terceiro setor que firmem parceria com o INSS por meio de Acordo de Cooperação Técnica.

9. Fala-se em 'abertura de exigência' quando o servidor identifica a necessidade de apresentação, pelo requerente, de documentos adicionais necessários para a análise do direito. Chama-se 'cumprimento de exigência' a resposta do beneficiário ao pedido do analisador, que deve ser atendido no prazo máximo de 30 dias.

10. O GET (Gerenciador de Tarefas) é a plataforma para gerenciamento dos processos digitais de requerimentos de benefícios. Ao acessar o GET, o servidor visualiza sua lista de tarefas, ou seja, todos os requerimentos pendentes de análise que lhe foram distribuídos pelo gestor local.

11. Trata-se de requerimentos de benefícios devidos aos trabalhadores de centros urbanos, cujo processo de trabalho difere quanto aos benefícios de zonas rurais, variando, ainda, quanto à pontuação devida. 


\section{RESUMOS}

Este artigo tem como objeto a digitalização do atendimento no Instituto Nacional do Seguro Social - INSS, organização responsável pela operacionalização da política de Previdência Social do Brasil. Referenciais da Psicologia do Trabalho e da Ergonomia da Atividade fundamentaram estudo de terreno para compreender as condições de implementação do 'Projeto INSS Digital' e suas implicações para a atividade dos servidores. Evidenciou-se heterogeneidade no controle de produção e nos recursos para a apropriação das tecnologias em diferentes unidades. Com a intensificação do trabalho, as estratégias de regulação tentam equilibrar as exigências de produção com a proteção da saúde, através de esquemas de utilização das ferramentas informáticas que confrontam estes trabalhadores com sobrecarga adicional de trabalho, pela realização de várias operações simultâneas e pela necessidade de validar o trabalho com recurso ao papel, face aos imponderáveis que o suporte digital traduz nesta fase e face à experiência ainda a construir na sua resolução.

Este artículo tiene por objeto la digitalización del trabajo en el Instituto Nacional del Seguro Social - INSS, la autarquía federal responsable de la ejecución de la política de Previsión Social en Brasil. Con el apoyo del marco teórico de la Psicología del Trabajo y de la Ergonomía de la Actividad se llevó a cabo un estudio de campo orientado para la comprensión de las condiciones de ejecución del 'Proyecto INSS Digital' y sus implicaciones para la actividad de los servidores. Se pudo evidenciar la heterogeneidad en el control de producción y en los recursos para facilitar la apropiación de las herramientas tecnológicas por parte de los trabajadores de las diferentes unidades. Con la intensificación del trabajo, las estrategias de regulación elaboradas intentan equilibrar las exigencias de la producción con la protección de la salud, mediante esquemas de uso de herramientas informáticas que ponen los trabajadores frente a una sobrecarga adicional de trabajo, ya que tienen que realizar múltiples operaciones simultáneas y necesitan validar el trabajo usando el papel, teniendo en cuenta los imponderables que el soporte digital acarrea en esta etapa y la experiencia que aún falta construir para su resolución.

Cet article traite de la numérisation du travail au sein de l'Institut National de la Sécurité Sociale - INSS, entité publique responsable de l'opérationnalisation de la politique de Sécurité Sociale brésilienne. Basée sur un référentiel théorique issu de la Psychologie du Travail et de l'Ergonomie de l'Activité, une étude de terrain a été réalisée afin de comprendre les conditions de mise en œuvre 'du Projet INSS Digital' et des conséquences de ce dernier sur l'activité des salariés. On a mis en évidence une hétérogénéité dans le contrôle de production et les recours permettant de faciliter l'appropriation des outils technologiques par des travailleurs de différents secteurs. Face à l'intensification du travail, les stratégies de régulation essayent d'ajuster les exigences de production à la protection de la santé, par le biais de schémas d'utilisation des outils informatiques qui confrontent ces travailleurs à une surcharge de travail, à la réalisation de plusieurs opérations simultanées et à la nécessité de valider le travail avec l'utilisation du papier, compte tenu des imprévus générés par le support numérique et au manque d'expérience face à ce nouveau système.

The scope of this paper is the digitalization of the service at the National Institute of Social Security - INSS, the federal institution in charge of implementing the Brazilian Welfare Services policy. Based on the framework of Work Psychology and Activity-centered Ergonomics, a field study has been carried out in order to understand the conditions under which the 'Digital INSS Project' has been implemented and their impact on the activity performed by the public servants. It revealed the heterogeneity in terms of production control and resources to enable 
the appropriation of technological tools by the workers from different units. Given the intensification of work, the regulatory strategies try to balance the production demands and the health preservation. They do so through schemes to use the computer tools that confront these workers with additional workload, given the accomplishment of several simultaneous operations and the necessity to validate the work using paper, in the face of the unexpected generated by the digital support and the experience still to be built in its resolution.

\section{ÍNDICE}

Mots-clés: numérisation, activité professionnelle, stratégies de régulation, technologie Palabras claves: digitalización, actividad laboral, estrategias de regulación, tecnología Palavras-chave: digitalização, atividade de trabalho, estratégias de regulação, tecnologia Keywords: digitalization, work activity, regulation strategies, technologies

\section{AUTORES}

\section{SACHA PINHEIRO}

Faculdade de Psicologia e Ciências da Educação, Universidade do Porto. Rua Alfredo Allen, 4200-135, Porto, Portugal.

sachapinheiro@gmail.com

\section{MARTA SANTOS}

Centro de Psicologia da Universidade do Porto, Faculdade de Psicologia e Ciências da Educação, Universidade do Porto. Rua Alfredo Allen, 4200-135, Porto, Portugal. marta@fpce.up.pt

\section{LILIANA CUNHA}

Centro de Psicologia da Universidade do Porto, Faculdade de Psicologia e Ciências da Educação, Universidade do Porto. Rua Alfredo Allen, 4200-135, Porto, Portugal. lcunha@fpce.up.pt 